\title{
Democracia participativa na Venezuela contemporânea
}

\author{
José Gilberto BiserRa Maia \\ Raimundo Jovanil Pereira Oliveira \\ Mônica Dias Martins
}

RESUMO: Esse artigo busca refletir a democracia participativa na Venezuela contemporânea, por meio das misiones bolivarianas e dos consejos comunales, como expressão do poder popular na construção do socialismo do século XXI. Essa experiência participativa requer diagnósticos, avaliações e possíveis mudanças de rumo para atender as promessas contidas nos instrumentos legais e discursivos, com pretensões de construir a democracia participativa e protagônica.

PALAVRAS-CHAVE: Democracia Participativa. Misones Bolivarianas. Consejos Comunales.

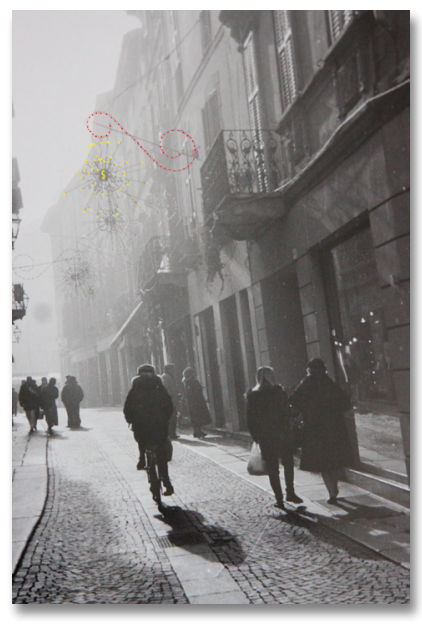

\section{Participatory democracy in contemporary Venezuela}

\section{José Gilberto BiserRa MaIA}

Doutorando do Programa de Pós-Graduação em Políticas Públicas da Universidade Estadual do Ceará (PPGPP/UECE).

E-mail: gmaia3@gmail.com

\section{Raimundo Jovanil Pereira Oliveira}

Doutorando do Programa de Pós-Graduação em Políticas Públicas da Universidade Estadual do Ceará (PPGPP/UECE). E-mail: jovanil@hotmail.com

\section{Mônica Dias Martins}

Professora da Universidade Estadual do Ceará (UECE), coordenadora da rede de pesquisadores Observatório das Nacionalidades e editora do periódico Tensões Mundiais.

E-mail: monica.martins@uece.br
ABSTRACT: This article seeks to reflect participatory democracy in contemporary Venezuela through Bolivarian missions and communal councils as an expression of popular power in the construction of 21 st century socialism. This participatory experience requires diagnoses, assessments, and possible changes of course to fulfill the promises contained in the legal and discursive instruments intended to build participatory and protagonist democracy.

KEYWORDS: Participatory Democracy. Bolivarian missions. Communal Councils.

RECEBIDO: $19 / 08 / 2019$

APROVADO: $23 / 11 / 2019$ 


\section{Introdução}

A Revolução Bolivariana, iniciada na Venezuela, com a chagada de Hugo Chávez ao poder, em 1998, foi por ele proclamada democrática, participativa e protagônica. Posteriormente, após a tentativa de golpe em 2002, o paro petrolero em 2002 - 2003 e o referendo revogatório em 2004, Chávez promoveu uma mudança de rumo, ao adotar como horizonte a construção de um Estado Comunal, de modo a ser expressão definitiva do novo socialismo ${ }^{1}$ e convencer da impossibilidade de alternativa para a humanidade apontada pelo capitalismo. Hugo Chávez buscou inspiração histórica e simbólica na figura de Simón Bolívar (1783 - 1830), lendário personagem que participou ativamente das lutas pela independência da América Latina, nas primeiras décadas do século XIX, até então colonizada pela metrópole espanhola. Assim, Chávez adotou o termo "bolivariano" para identificar suas ações políticas internas, as quais pudessem servir de inspiração e exemplo para além das fronteiras venezuelanas.

Entretanto, a partir de 2005, esse processo político apresentou como retórica e prática a idealização de uma nova forma política de se pensar e efetivar o socialismo, distinguindo-se das experiências ditas socialistas do século XX, encarnadas no chamado socialismo real.

Diante desse cenário, se torna cada vez mais relevante um olhar cuidadoso e responsável para experiências políticas que apontem como horizonte uma alternativa participativa do cidadão nos processos políticos, como forma de incrementar e rejuvenescer o modelo democrático, mesmo que não seja pelas estratégias formais do modelo representativo. Conhecer as experiências autoproclamadas participativas se torna fundamental para uma tomada de ciência, pois a democracia não se efetiva apenas por um caminho e as alternativas para a construção de uma democracia de alta intensidade (SANTOS, 2002; SANTOS; AVITZER, 2002) podem estar postas e em curso. Carece-se, portanto, da apropriação do conteúdo dessas experiências para que se verifique sua viabilidade histórica.

1 Definido como socialismo do século XXI, o qual teria como espinha dorsal a democracia participativa (DIETERICH, 2005). 
Com a Revolução Bolivariana, foram articuladas e executadas ferramentas participativas, demonstrando um esforço para não se apegar única e exclusivamente ao exercício representativo, no qual, em regra, a atuação do cidadão se encerra no ato do voto. Entre essas ferramentas, se destacam as misiones bolivarianas e os consejos comunales. Esse trabalho, então, traça um breve panorama da democracia participativa desenhada pela Revolução Bolivariana, a partir de uma abordagem qualitativa e uma investigação bibliográfica e documental. No primeiro tópico, se discute compreensões teóricas e conceituais de democracia participativa. No segundo, enfocam-se as experiências participativas das misiones bolivarianas e dos consejos comunales, que operam na Revolução Bolivariana como expressão máxima do poder popular, essenciais para a construção do socialismo do século XXI. Por fim, entende-se que, diante dos fracassos da representação, a democracia participativa pode ser vista como novidade na política recente da região, embora careça de reflexões que atestem sua potencialidade como alternativa ao modelo democrático tradicional, bem como possa construir as bases do socialismo renovado, como proclama a Revolução Bolivariana.

\section{Democracia participativa: notas teóricas}

Entende Miguel (2017, p. 110) que valorizar o cidadão, incentivando sua autonomia na vida cotidiana, pode significar uma estratégia para a obtenção de um melhor diálogo com os representantes, pois "[...] é a participação que pode ampliar seus horizontes, dar a eles o entendimento da lógica da política, torná-los mais capazes de intervir de maneira consciente, até mesmo estratégica, na formulação de seus próprios interesses". O autor reafirma ainda que "[...] qualquer alternativa de aprimoramento democrático parece passar pela ampliação das possibilidades de participação popular direta" (MIGUEL, 2017, p. 111).

A participação reconfigura a representação, sem destruí-la. Este autor, porém, pondera que "[...] na nova maneira de pensar a relação entre os dois polos, a representação reconfigurada simplesmente dissolve a participação" (MIGUEL, 2017, p. 111). 
Assim, Miguel (2017) assevera que, ao se acreditar que as camadas populares, historicamente excluídas dos processos políticos, não tinham condição de exercer sua cidadania, em função da incapacidade política, não se deveria insistir com a estratégia da participação. Portanto, ele permite concluir que as tarefas decisórias cabiam única e exclusivamente aos representantes, mesmo que estes não atuassem em consonância com os interesses dos representados.

Na concepção liberal de democracia, se duvida da capacidade dos sujeitos coletivos e da sociedade civil de exercerem o poder, historicamente concentrado nas mãos das elites. Já os defensores da democracia social anunciam que "[...] a participação efetiva de sujeitos coletivos no governo irá desenvolver e aperfeiçoar a própria democracia". (TEIXEIRA, 2015, p. 210). Para Teixeira (2015), a participação é um elemento primordial no desenvolvimento de um ser humano consciente dos seus interesses e de seu papel social. A efetivação do sistema participativo emerge e se fortalece no âmbito da dinâmica local. Nesse sentido, é importante a passagem de uma estratégia consumista para a compreensão da atuação individual e, principalmente, coletiva.

As experiências de democracia participativa em nível local, que emergiram no final dos anos 1980, ${ }^{2}$ são referendadas por Santos $(2016,2007,2002)$ como dimensões de fortalecimento democrático para além da democracia representativa. Seus resultados positivos foram surpreendentes até para seus protagonistas e suscitaram curiosidades dos líderes municipais das cidades brasileiras, de toda América Latina e até da Europa. A partir da prática dos orçamentos participativos, mesmo com variações de aplicabilidade, o Banco Mundial chegou a reconhecer suas virtudes e recomendar sua adoção (SANTOS, 2016).

Conforme Santos (2016), a forma de democracia participativa, além de emblemática, se tornou pujante nas últimas décadas. A exemplo dos orçamentos participativos, surgiram os conselhos municipais e estaduais, com funções consultivas e deliberativas,

2 Os Orçamentos Participativos em Porto Alegre foram as primeiras dessas experiências. 
em alguns casos, na definição de políticas sociais; as consultas populares; os referendos; o protagonismo dos movimentos indígenas, com reconhecimento de um tipo de democracia comunitária, constituída pelos processos de discussão e deliberação ancestrais das comunidades indígenas. E arremata Santos (2016, p. 126), que "[...] essa vasta experiência democrática traduziu-se em articulações novas e até então inimagináveis entre democracia representativa e democracia participativa". O autor pontua que não se trata de eliminar a democracia representativa e substituí-la por um novo modelo, seja participativo ou comunitário, que possa ser considerado mais genuíno, mas articular todos os tipos disponíveis. Na sua concepção, "[...] é essa vastíssima experiência de lutas democráticas que nos permite hoje ampliar o cânone democrático e produzir teorias de democracia que vão muito além da teoria liberal" (SANTOS, 2016, p. 126).

Dagnino, Olvera e Panfichi (2006) recordam que a disputa pela democracia na América Latina, no tempo presente, se estabelece entre os projetos neoliberal e o democrático-participativo, tendo como pano de fundo a herança autoritária que marca a história do continente e sua constante persistência. Nesse sentido, acreditam que o avanço democrático no continente depende do tipo de projeto participativo que pode confrontar, de forma prática e teórica, o modelo elitista na busca transformadora da sociedade e, assim, ser possível encontrar alternativas capazes de entender os dilemas da democracia participativa diante da conjuntura hegemônica neoliberal. Esses autores diagnosticam que há grande disputa envolvendo o projeto neoliberal, privatizador de significativas áreas das políticas públicas, as quais se utilizam de um discurso participacionista, com revalorização simbólica da sociedade civil, entendida como sendo o terceiro setor, e o projeto democrático participativo. Ressaltam também que, entre tais processos, ainda há espaços para o surgimento e desenvolvimento de projetos autoritários que respeitam as instituições democráticas apenas no aspecto formal.

No entanto, a crise partidária no mundo e na América Latina se estabelece pela ausência de nexo entre os partidos e os setores da sociedade, no contexto das competições políticas, envolvendo suas formas e condições. Assim, a política se torna informal, 
transcorrendo para além do âmbito institucional, se relacionando com redes informais e estabelecendo acordos de curto prazo com inúmeros e distintos personagens (DAGNINO; OLVEIRA; PANFICHI, 2006). Esse quadro leva os autores a reconhecerem como recorrente a opressão, a reivindicação e o confronto na relação que envolve a sociedade civil e o Estado.

Chama atenção o ponto de vista de Addor (2016) para a necessidade de se aprofundar o entendimento do que seria participação política para a tomada de decisões no espaço público. No seu entendimento, a consolidação de novas estruturas participativas será garantida "[...] pela existência de cidadãos que tenham capacidade de dar-lhes vida, que possuam a cultura política necessária para mudar o poder político" (ADDOR, 2016, p. 21). O autor, então, avalia como relevante o estudo de experiências transformadoras, entendendo que o modelo representativo liberal já não se caracteriza como suficiente para atender as complexas demandas sociais da América Latina e que o aumento da participação nos espaços públicos de tomada de decisão é indispensável para a conquista da cidadania e a consolidação de sistemas efetivamente democráticos, nos países latino-americanos.

Ele elenca pontos que considera chaves para orientar os povos e as comunidades a serem os mais transformadores possíveis e capazes de incorporá-las nas estratégias de luta pela democracia participativa. Esses pontos-chave são:

[...] retomada de discussão sobre a democracia [...]; [...] maior aproximação entre o sistema político e sociedade [...]; [...] transformar o Estado, levando as lutas populares para seu interior $[. .] ;.[. .$.$] rever interação democracia e$ capitalismo [...]; [...] articular um projeto participativo-democrático de âmbito latino-americano, uma proposta de consolidação do poder popular na região, que alimente a perspectiva utópica, de transformação da sociedade, por meio, principalmente, da disseminação e articulação dessas experiências de transformação política. (ADDOR, 2016, p. 28 - 29).

Nessa perspectiva, Addor (2016) esclarece que há, no processo de formação democrática no continente latino-americano, distintas realidades e especificidades, que merecem ser revisitadas com 
base histórica e das práticas desenvolvidas, no sentido de consolidar um referencial teórico mais adequado às diversas características dos processos desenvolvidos. Esses procedimentos enfrentam, na sua compreensão:

[...] de um lado, cultura política tradicional da região, que promove a hierarquia, o distanciamento da sociedade do âmbito político, a prática clientelista e assistencialista, o personalismo, a troca de favores, a corrupção; de outro, uma estrutura democrática representativa conservadora que dificulta uma ampla participação, pois prioriza a decisão e a vontade dos governantes em detrimento das populares, permitindo que o poder econômico seja automaticamente transformado em poder político". (ADDOR, 2016, p. 437).

Nesse sentido, Addor (2016, p. 438) sustenta que há uma tendência de culpabilizar o Estado por ser um ente que não permite avanços profundos de democratização, especialmente quando a "[...] heterogeneidade presente tanto entre grupos e organizações da sociedade civil quanto entre as diferentes correntes e atores do estado torna complexa essa análise simplória, binária, e exige um cuidado maior na análise dos campos". É, portanto, um desafio mais do que urgente para superar essa estrutura e cultura da política tradicional, a viabilização de mecanismos de participação popular como estratégia de fortalecimento da tese democrática.

Conforme as observações de Garcia Linera (2015), ${ }^{3}$ emergiu um novo cenário na conjuntura política do século XXI, como fundamental para o desenvolvimento e o fortalecimento da democracia no continente americano e no mundo. Ele percebe que há uma novidade política na América Latina recente e avalia que a democracia não pode ser reduzida exclusivamente ao voto, ou seja:

[...] Que o voto, a representação é um elemento fundamental da constituição democrática dos Estados, garante direitos, garante a pluralidade. Mas que, paralela e complementariamente há outras formas do enriquecimento do democrático. Essas

3 Intervenção no Fórum Emancipación y igualdad, debate alternativas al neoliberalismo, realizado em Buenos Aires, no ano de 2015. 
formas de enriquecimento do democrático é a praça, é a rua, é a democracia das ruas, é a democracia plebeia, é a democracia que exercemos nas marchas, nas avenidas, nos sindicatos, nas assembleias e nas comunidades. (GARCIA LINERA, 2015, [s./p]).

Desse modo, o referido pensador e político entende que há possibilidades e mecanismos que forjam o rejuvenescimento e a transformação da democracia ao "[...] abandonar seu estado de instituição fóssil, repetitiva, enfadonha e monopolizada por elites ou castas, é a vigência, o vigor e o complemento da democracia das ruas, da democracia das organizações, da força dos movimentos sociais [...]" (GARCIA LINERA, 2015, [s./p.]). A governabilidade institucional é pensada como o novo na América Latina, na medida em que se combine a força eleitoral com a força das ruas. Haverá, na sua concepção, governabilidade nos Estados latino-americanos e reforço da dinâmica democrática quando simultaneamente "[...] o povo delibera, o povo participa, o povo assume compromissos, o povo propõe ao Estado e ao governo em seus âmbitos de organização local, territorial, da rua, da praça, da assembleia [...]". (GARCIA LINERA, 2015, [s./p.]).

Santos (2016) cita os casos da Venezuela, da Bolívia e do Equador como exemplos importantes da capacidade de experimentar em busca da ruptura com as relações de poder existentes. Ou seja:

[...] Criar espaços políticos a partir do início da mudança das relações de poder, mas que uma vez criados permanecem abertos à criação e à inovação, é algo que a teoria política liberal ou marxista nunca foi capaz de admitir porque confundiu tomada de poder com exercício do poder. (SANTOS, 2016, p. 129).

Não basta chegar ao poder. É necessário que se utilize o exercício do poder para buscar respostas transformadoras por meio dos processos políticos. As tentativas e experimentações podem ser validadas, tanto de forma simultânea quanto de forma sequenciada. A crença nas soluções provisórias e experimentais possibilita o debate político aberto na construção de soluções institucionais e normativas (SANTOS, 2016). 
Pedraza Mora (2014), ao refletir as origens e as variações acerca da democracia participativa, enfatiza a variante da democracia radical por entender que, na atualidade, as experiências participativas não têm ultrapassado os limites do local. Ele ressalta que dificilmente essas experiências não sejam cooptadas pelas recorrentes lógicas elitistas, representativas e excludentes. Nesse cenário, corre-se o risco de se desenvolver experiências democráticas que possam limitar mais do que emancipar as relações sociais, “[...] que posibilite repensar la democracia más allá de arreglos institucionales universalizantes, desconocedores de la diversidad presente en distintos contextos" (PEDRAZA MORA, 2014, p. 72).

O modelo participativo de democracia, no olhar desse autor, alude em geral a processos de reconhecimento do exercício do poder, que implicam a maximização das possibilidades de inserção dos cidadãos na gestão e na construção do público. Nessa reflexão, Pedraza Mora (2014) identifica as correntes pluralista e societal nos debates sobre a viabilidade do modelo participativo, sendo que:

[...] el societal que no se limita a la participación a través de las instituciones políticas; y propone la construcción de colectividades donde los ciudadanos participen activamente como una posible vía de superación de las limitaciones propias de la democracia representativa junto al ethos político que conlleva pensar que otros decidan el destino de nuestras vidas y trabajar por la construcción de formas políticas alternativas a la democracia representativa. (PEDRAZA MORA, 2014, p. 72).

Desse modo, a democracia participativa pode ser um canal de atuação do cidadão capaz de abrir e legitimar espaços de poder, rompendo uma horizontalidade que a democracia exige. Assim, será urgente avançar em formas de indagação e experimentação de modelos radicais de democracia que sejam capazes de construir novas instituições, novas emergências de variadas identidades e subjetividades. Ademais, uma experiência de "[...] participación efectiva en la construcción de lo público y emancipadoras para los seres humanos" (PEDRAZA MORA, 2014, p. 98). 
De acordo com Bruce (2011), têm ocorrido expressões significativas de busca por um otro mundo posible, ${ }^{4}$ embora com diferentes níveis de aprofundamento e radicalidade. Essas experiências apontam diferentes soluções para a problemática da democracia e a autora pensa que "[...] Apesar de cada experiência corresponder ao seu contexto específico e possuir características próprias, todas vão na direção da busca por uma forma formante, que viabilize a prática de mandar obedecendo" (BRUCE, 2011, p. 222).

Já El Troudi, Harnecker e Bonilla (2010) estão convencidos de que a participação ativa dos cidadãos conscientes atua como insumo vital para o aprimoramento, o aprofundamento e a consolidação de um processo revolucionário. Os autores se referem especificamente aos eventos emergidos na Venezuela, a partir da chegada de Hugo Chávez ao poder, e falam da necessidade de:

Rearmamento político-ideológico que passa pela reflexão e por um balanço crítico sobre a atividade empreendida; pela identificação das ameaças, pelo conhecimento da diferença entre o modelo de sociedade que explora e outro que liberta; pela elaboração da estratégia; pelo reconhecimento do terreno sobre o qual se atua; e, sobretudo, em tirar proveito do poder delegado pela organização e da participação popular. (EL TROUDI; HARNECKER; BONILLA, 2010, p. 14).

Assim, eles afirmam que a participação constitui um conceito único, estável e referido apenas ao aspecto político, sendo “[...] uma dinâmica através da qual os cidadãos se envolvem de forma consciente e voluntária em todos os processos que lhes atingem direta ou indiretamente" (EL TROUDI; HARNECKER; BONILLA, 2010, p. 21).

A participação permite aos cidadãos ocupar os espaços políticos de tomada de decisão, com a possibilidade de desenvolvimento de políticas públicas imbricadas com suas experiências e demandas. Por meio de uma recorrente prática de participação, se possibilita a derrota da exclusão política, uma vez que exercendo a cidadania, o povo protagoniza o sentido amplo da democracia

\footnotetext{
4 A autora cita o movimento Zapatista no México; a democracia participativa e protagônica na Venezuela; os movimentos indígenas, as experiências participativas no Equador e a refundação do Estado boliviano numa perspectiva plurinacional. Para saber mais, ver Bruce (2011).
} 
como poder do povo e para o povo (EL TROUDI; HARNECKER; BONILLA, 2010).

O que esses autores refletem se aproxima do diagnóstico de Santos $(2002,2007,2016)$ e Santos e Avritzer (2002), os quais identificam como uma das patologias da democracia representativa a não atuação dos cidadãos eleitores, para além do ato de votar e que, na maioria dos casos, os representados não enxergam legitimidade de fato nos representantes por eles escolhidos. Assim, esse mecanismo de fortalecimento dos instrumentos e mecanismos de participação potencializam a cidadania, bem como fortalecem a democracia, ao contrário dos defensores da representação que avaliam o voto como o único procedimento político do cidadão.

El Troudi, Harnecker e Bonilla (2010) também destacam que a participação é um processo constituído de constante aprendizado, que não é decretado de cima para baixo. A construção da participação indica uma lenta transformação cultural, pois os frutos dessa atuação participativa não são colhidos no curto prazo. Eles ressaltam ainda, como desafio a ser superado, o rompimento com a tradição cultural da intermediação política, da representação e do clientelismo, sendo, assim, possível alcançar a suplantação das práticas históricas individualistas, herdadas da sombra perversa da política neoliberal que ronda as relações humanas. Desse modo:

Torna-se especialmente importante enfatizar no desenvolvimento de práticas reflexivas a avaliação permanente das conquistas alcançadas através da participação, relacionando-as com as necessidades de conjuntura e com as estratégias da própria comunidade. Atrever-se a pensar e a entender o que ocorre na realidade na qual vive e participa é o caminho certo para conseguir a independência de pensamento, e constitui o melhor antídoto contra a manipulação da participação comunitária [...]. (EL TROUDI; HARNECKER; BONILLA, 2010, p. 25).

Por meio desse entendimento, a educação popular assume grande importância como ferramenta para entender a realidade, os conflitos e as necessidades de mudanças. Portanto, a trajetória que leva ao enraizamento das experiências de participação perpassa por um acurado fortalecimento pedagógico do que seja a cidadania e o seu valor transformador. 
Como vantagens para as comunidades, El Troudi, Harnecker e Bonilla (2010) elencam a elevação da autoestima popular, o respeito às diferenças, a superação das divisões e a politização, que possibilitam o crescimento e o desenvolvimento de valores e novas sensibilidades.

A realidade social será transformada a partir do conhecimento pleno das necessidades e demandas da comunidade, por meio de um diagnóstico completo para que a práxis participativa oportunize intervenções significativas. Esse diagnóstico deve ser realizado, sobretudo, por quem tem o melhor conhecimento das necessidades do lugar: os habitantes locais que sabem a situação em que vivem. El Troudi, Harnecker e Bonilla (2010, p. 74), destacam que o "[...] diagnóstico participativo permite identificar, ordenar e hierarquizar os problemas comunitários e, por isso, permite que os moradores cheguem mais bem preparados para a formulação do orçamento participativo".

É recorrente nas reflexões sobre a democracia, sobretudo na atualidade, as limitações em atender as demandas sociais dos cidadãos por meio do modelo de representação. Sendo assim, Revélez Vazquez (2017) reconhece nas experiências participativas empreendidas pelos recentes governos progressistas na América Latina, especialmente com a introdução de plebiscitos, referendos, revogação de mandatos e iniciativas legislativas cidadãs, estratégias certeiras para solucionar as lacunas na representação política. Na sua percepção:

[...] Al superar uma visión elitista de la política y una concepción electoral de la democracia, estos mecanismos pueden fomentar la participación, la deliberación, la transparencia, la responsabilidad política y, em esencia, la intervención directa del sujeto en la toma de decisiones sin trastocar las bases dela forma de gobierno democrática vigente en la mayoría de los países latinoamericanos (REVÉLEZ VAZQUEZ, 2017, p. 71).

Por meio de mecanismos de intervenção cidadã na formulação de propostas de políticas públicas, os governantes podem ceder poder político e recursos econômicos a indivíduos comuns. Segundo Revélez Vazquez (2017, p. 93), isso trata-se de estratégia 
que "[...] potencia interés, acción y compromiso de los ciudadanos, quienes tenderán a ser más vigilantes del comportamiento de los gobernantes y, en consecuencia, más atentos, cuidadosos en sus decisiones y, previsiblemente, más críticos".

Em contrapartida, Massal (2010) identifica limitações e obstáculos, mesmo diante de um contexto que aparentemente favorece a legitimação das experiências participativas, e questiona alguns postulados teóricos e empíricos que relacionam representação, participação e fortalecimento democrático. Com certa preocupação em torno das modalidades de alcance da participação, ele pondera que os esforços para desenvolver alternativas de governo, a partir dos movimentos sociais e políticos que contestam o sistema político representativo, no âmbito nacional ou local, têm apresentado desilusões, no que diz respeito a mudanças sociais e políticas:

[...] Los obstáculos para lograrlo no son pocos, teniendo en cuenta que las leyes y constituciones poco o nada se aplican, que los partidos políticos, al ser excluidos de los dispositivos participativos, los entorpecen en el nivel local o nacional, y que muchos de los dispositivos existentes requieren para su éxito de una efectiva y signifcativa transferencia de recursos fnancieros a los gobiernos locales (MASSAL, 2010, p. 90).

Massal (2010) ainda entende como paradoxal que, mesmo diante de um consenso em torno da democracia participativa, exista tantas dificuldades em implantá-la. Na sua visão, isso ocorre devido a uma dispersão ou fragmentação conceitual, no desenho e na implementação dos dispositivos ditos participativos, com variedade de práticas e objetivos de acordo com quem os promove. Todavia, mesmo diante dos discursos políticos em favor da democracia participativa, podem ser observados vácuos e limitações nos processos participativos até então levados a cabo, o que contribui para um certo desvanecimento que coloca em dúvida as esperanças levantadas com a democratização da democracia por meio da participação (MASSAL, 2010).

Lander (2005) compreende que se torna essencial a aplicação de políticas públicas universais, que apontem para uma equidade social e sejam capazes de superar as desigualdades políticas 
e exclusões culturais. A base para tais políticas públicas deve ser ancorada na participação, que, na sua visão, tem o duplo sentido de garantir a inclusão social e a construção da cidadania. Ademais, "[...] a participação converte-se numa ferramenta para transformação das condições de vida" (LANDER, 2005, p. 208).

\section{Da teoria à prática na Venezuela contemporânea}

A nova Constituição venezuelana, promulgada em 1999, trouxe para o debate contemporâneo a discussão sobre a aplicabilidade da democracia participativa, pois, dos seus 350 artigos, 70 deles preconizam a participação popular. Entre as novidades, apontam-se: os poderes cidadão (poder popular) e o poder eleitoral; o Parlamento Unicameral (Assembleia Nacional com 167 assentos); os instrumentos da democracia participativa: plebiscitos, referendos, referendo revogatório(recall); a consulta popular; as assembleias de cidadãos e cidadãs, a autogestão, a cogestão e as cooperativas. Nela, há ainda a inclusão dos direitos humanos e dos direitos dos indígenas, bem como destaca no artigo $5^{\circ}$ que "[...] A soberania reside intransferivelmente no povo" (CRBV, 1999).

Contudo, ao longo da história venezuelana do século XX, já havia um conjunto de experiências de participação, a saber: a Liga dos Colonos, nos anos 1930; a derrubada da ditadura de Marco Perez Jimenez, em janeiro de 1958; as Juntas Profomento: as melhorias estruturais dos bairros, nos anos 1960; a associação de vizinhos para tratar de questões comunitárias, nos anos 1970; a Comissão para Reforma do Estado (COPRE), ${ }^{5}$ exigindo eleições para prefeitos e governadores, em 1985; o Caracazo, uma revolta popular que expressava a crise do Estado e do Pacto de Punto Fijo, em1989; os movimentos populares nos bairros, nos anos 1990, reivindicando participação na esfera pública, defesa de orçamentos participativos e consultas públicas, dentre outras demandas (ADDOR, 2015). Dessa forma, em 1999, quando o governo convoca o referendo para a abertura da Assembleia Nacional Constituinte, com objetivo de reformular o Estado, a participação popular não era novidade para os venezuelanos.

5 Até então, os governantes eram escolhidos pelo Executivo Federal. 
Petras (2007) lembra que, diante de argumentos de autoritarismo do governo, as mudanças políticas no país foram debatidas e aprovadas pela maioria dos parlamentares livremente eleitos, agrupando as emendas nos blocos de mudanças políticas, econômicas e sociais. Para esse autor:

Entre as mudanças políticas, a mais importante é a criação de novas formas democráticas localizadas de representação política, em que recursos estatais serão repassados à comunidade eleita e às instituições locais, ao invés de aos governos estaduais e municipais, corruptos e clientelistas. Esta mudança rumo à descentralização encorajará uma maior prática da democracia direta, em contraste às tendências oligárquicas incrustadas no atual sistema representativo centralizado. (PETRAS, 2007, p. 77).

As Misiones Bolivarianas, ${ }^{6}$ decretadas por Hugo Chávez em 2003, constituíram as primeiras ações diretas do governo para solucionar, de forma mais imediata, os graves problemas sociais que assolavam a sociedade venezuelana e também para atender as promessas participativas delineadas na nova Constituição. Tratase de programas sociais com vistas a satisfazer as necessidades de saúde, educação, moradia, cultura e lazer, especialmente aos mais humildes, na busca da universalização dos direitos básicos. Addor (2016) chama a atenção para o sucesso das missões, devido à desburocratização das ações, ao negar enfoques convencionais que obstaculizavam a agilidade para a obtenção dos resultados. Desse modo, o autor enxerga que a ação comunitária é o elemento central do funcionamento das missões.

De acordo com a publicação do Ministério do Poder Popular para Comunicação e Informação (MPPCI), em 2007, as missões bolivarianas atuavam como uma das bases do novo Estado socialista, de direito e justiça, uma vez que:

6 Cada missão tem, na maioria dos casos, o nome ou pseudônimo de um homem ilustre e herói nacional, incluindo indígenas. Destacam-se: Barrio Adentro, Guaicaipuro, Hábitat, Identidad, Cultura, Mercal, Miranda, Piar, Robinson, Ribas, Sucre, Vuelta al Campo, Vuelvan Caras, Milagro, Sonrisa, Ciencia, Negra Hipólita e Missão Caricuao. (OM, 2007). 
[...] su ejecución promueve la superación de la democracia representativa y el Estado capitalista, apuntando hacia la consolidación de una democracia participativa y la creación de un Estado socialista genuino, que se nutre de las experiencias de la colectividad nacional. (MPPCI, 2007, p. 12 - 13).

Entretanto, são os Consejos Comunales (CCs) a maior expressão do viés participativo, empreendido pelo governo Chávez, a partir de 2005. Naquele momento, o governo decide ressignificar a gestão depois dos eventos de 2002, 2003 e 2004, que quase lhe custaram a perda do mandato. A promulgação da Ley Orgánica de los Consejos Comunales (LOCCs), em abril de 2006, institucionaliza os CCs. Essa mudança de rumo político do presidente é rememorada por estudiosos, que destacam a fala do próprio presidente:

Você se lembra, e o país se lembra, de que, em alguma ocasião, foi ingenuamente esboçada aquela tese da terceira via [...] mas cheguei aqui e começou aquela dinâmica em torno da minha pessoa, em torno da minha gestão, fui aprendendo na realidade, fui estudando, fui viajando pelo mundo e, em poucos anos, especialmente depois do golpe de abril de 2002. Depois da investida imperialista com aquela ação selvagem de sabotagem econômica e de terrorismo, me dei conta de que o único caminho para sermos livres, para que a Venezuela seja livre, independente, é o caminho do socialismo (SANTOS, 2018, p. 28).

Chávez, reeleito em 2006, estabeleceu como projeto para levar o país até o socialismo do século XXI os seguintes motores: lei habilitante, reforma socialista da constituição, educação popular, nova geometria do poder e expansão do poder comunal - os CCs (ADDOR, 2016; BRUCE, 2015).

Nessa perspectiva, os CCs são microgovernos constituídos no interior das comunidades, compostos pelos próprios moradores, possuidores de poder deliberativo e executivo sobre a gestão das políticas locais. As comunas são agregação de CCs e outras organizações civis, articuladas em torno de um projeto sócio produtivo que potencialize as riquezas da região correspondente. Com esse caminho, se construiria o Estado Comunal, que seria a articulação 
de federações e confederações de CCs e/ou comunas atreladas ao desenvolvimento econômico endógeno e autossustentável do país (BRUCE, 2015).

Com a LOCCs de 2006, se pretende articular, em uma única instituição, os diferentes grupos de trabalho no interior das comunidades. Para Bruce (2015, p. 175), “[...] trata-se de mobilizar pequenos grupos locais, com abrangência máxima de 400 famílias, aproximadamente 200 a 400 famílias nas cidades, 20 nas áreas rurais e 10 nas comunidades indígenas e inserir a população na gestão das políticas da comunidade". Através dos ciclos comunais, se organizam os CCs, por meio das seguintes fases: diagnóstico, plano de ação, orçamento, execução e controladoria geral.

A partir da publicação da lei, se regularizam as estruturas de funcionamento dos CCs, criando a Assemblea de Ciudadanos y Ciudadanas, como instância máxima de tomada de decisão e deliberação para o exercício do poder comunitário, a participação e o protagonismo popular. Ainda há os Comités de Trabajo, a Unidad de Gestión Financiera, a Controladoria Social (responsável pela administração de recursos) e um Órgano Ejecutivo. (ADDOR, 2016; BRUCE, 2015). Afirma Bruce (2015) que a Controladoria Social realiza avaliação da gestão comunitária das atividades, recursos e administração dos fundos dos CCs. Esse mesmo autor diz que, nos bairros da favela 23 de Enero, em Caracas, “(...) as reformas sociais e estruturais necessárias eram atreladas à exigência de uma organização previa das classes populares" (BRUCE, 2015, p. 174).

Esse chamado à participação aparece de forma recorrente nos discursos oficiais ou documentos sobre a conjuntura venezuelana, com reiteradas menções à atuação popular como estratégia de tornar o cidadão protagonista da sua vida e corresponsável pelo destino do país. No caso das Comunas, o Parlamento Comunal se constitui como a instância máxima de tomada de decisão e cada uma deve construir seu Plan Comunal de Desarrollo, apontando seus objetivos, projetos e recursos. Além do Parlamento Comunal, são importantes outras instâncias, como: o Consejo de Planificación Comunal; o Consejo de Economía Comunal; o Banco de la Comuna e o Consejo de Controladoría Comunal (ADDOR, 2016). 
Chávez asseverou, em outubro de 2012, "o comuna o nada" e a organização política da Venezuela em comunas é explicada da seguinte maneira:

Y la construcción de las comunas es hoy un avance abierto, una potencialidad que se va desplegando sobre el territorio nacional. Porque en las comunas reside una cantidad de posibilidades: ser un nuevo Estado, una nueva política, una nueva economía. Es decir, una reorganización de la vida de las personas, en colectivo, de forma democrática y participativa: la nueva sociedad socialista. (TERUGGI, 2014, [s./p.]).

Críticas e limitações existem, mas afirma Teruggi (2014) que não se trata de fracasso. Mesmo que todo o processo revolucionário esteja sujeito ao insucesso, esse não é o caso:

Pero la razón comunera también como opuesta a la razón burocrática: la construcción comunal como la posibilidad de romper con la lógica burocrática, ineficiente. Es la puesta en marcha de una democracia directa -cruzada con una representativa-, de la responsabilidad, de la resolución colectiva para objetivos colectivos. Es el trabajo voluntario, el deseo de la trasparencia, la priorización de los intereses colectivos por sobre los individuales, de la ética revolucionaria. Es, puede ser, significa que ya está sucediendo en muchos lugares. (TERUGGI, 2014, [s./p.]).

Em 2016, quando a LOCCs completou dez anos, havia 45.776 conselhos registrados e dezenas se uniram a 1.504 comunas. Naquele ano, foram registrados mensalmente 367 novos conselhos, beneficiando os movimentos sociais, as organizações comunitárias e as comunidades indígenas (MPPC, 2016). De acordo com o MPPC, em 2019, existem 47.986 CCs e 3.135 comunas, englobando cerca de 14 milhões de pessoas de uma população de aproximadamente 32 milhões de habitantes. Um número impressionante, diante das dificuldades que se apresentam às comunas, pois existe grande dificuldade de unificação, por causa da instabilidade política do país e das relutâncias dentro do próprio governo (POZNANSKI, 2019). 
A politização da sociedade civil, a transformação da realidade (alteração da cultura política), a permissão da utopia, a organização das bases, a efetividade dos CCs, o intercâmbio com respeito ao lugar, novos espaços democráticos de poder popular, a tradicional estrutura da democracia liberal representativa, o comprometimento do Estado e a formalização do compromisso político são eixos importantes para a análise dos espaços participativos na Venezuela contemporânea (ADDOR, 2015).

É importante para o futuro a concertação entre Estado, patrões e trabalhadores, bem como a participação popular, uma vez que:

[...] Chávez, enquanto presidia a Venezuela, aplicou uma série de medidas que romperam com estrutura socioeconômica anterior, levando a um espinhoso enfrentamento com as elites, e vêm desenvolvendo um real processo de implementação de um poder popular, o que não é característica dominante no nacional-estatismo, mas talvez estado incipientemente presente no governo Jango. Resta-nos acompanhar como se desenrola o processo venezuelano, seguramente o mais transformador, com a morte de Chávez (ADDOR, 2015, p. 162).

Valorizar a participação política das camadas populares para fortalecer a autonomia, a incorporação e a aprendizagem política por aqueles até então excluídos, são fatores em grande medida subjetivos e de difícil avaliação, sem cair em simplismos e reducionismos, ao se observar essa experiência venezuelana pelas lentes da "democracia radical". Entretanto, segundo Bruce (2011), esses são elementos que potencializam as estratégias de reestruturação da via democrática. Nesse percurso:

Sem dúvida, a construção do Estado comunal venezuelano é permeada por conflitos, tensões dilemas e desafios. Para além da bipolaridade entre 'chavistas' e 'não chavistas', há um rico debate sobre os rumos do processo. Se um dia o debate sobre a democracia residiu na luta pela representação, depois pelo sufrágio universal, pela representação qualificada (isto é, a possibilidade de eleger representantes das classes trabalhadoras, classes mais pobres e, mais recentemente, minorias de todos os tipos) e, finalmente, pela participação 
política, é notório que hoje, o que se está discutindo na Venezuela é a qualidade dessa participação". (BRUCE, 2015, p.179).

Os caminhos tomados na Venezuela não são exclusivos, mas podem se configurar uma tendência a se refletir no continente, na perspectiva de que outro mundo é possível, mesmo que envolvam tensões entre dependências e autonomias, entre poderes constituintes e poderes constituídos (BRUCE, 2015).

Para Lander (2005, p. 215), as principais alterações ocorridas na Venezuela bolivariana foram na cultura política e nos processos de inclusão social, como uma conquista de uma sociedade mais democrática, ao ocorrer "[...] a incorporação como sujeitos da ação política e organizativa das maiorias pobres do país que se encontravam excluídas, não só historicamente como cada vez mais, nos últimos tempos".

Entretanto, anota Garcia-Guadilla (2018) que, mesmo representando a figura organizativa mais importante na atualidade, nos sectores populares, a julgar pela importância de seus objetivos e funções, assim como pela grande quantidade de conselhos criados e pelos altos valores de recursos econômicos, no processo participativo e comunal, são verificadas contradições e limitações de percurso. Entre tais, se destacam: diagnósticos incompletos dos problemas locais; dificuldade de tempo para capacitação dos participantes; não incorporação da imagem-objetivo da comunidade; carência de análise política da viabilidade de aplicação das decisões tomadas; não acompanhamento técnico das etapas do planejamento; não capacitação técnica; falta de transparência na gestão; cooptação partidária; exclusão devido à polarização política e casos de corrupção.

Os CCs focam na busca de solução de problemas imediatos da comunidade, por meio da ação da população, uma medida insuficiente para a garantia da democracia participativa, pois “(...) la participación no debeconstituir una carga más para la población de los sectores populares ni percibirse comoobligatoria" (GARCIAGUADILLA, 2018, p. 98). Garcia-Gadilla (2018) também avalia que a participação na Venezuela se utiliza de resultados distintos. De um lado, a inclusão simbólica da população desfavorecida, 
ao valorizar sua identidade e sua condição cidadã; por outro, a permissão para a exclusão daqueles cidadãos desconectados dos organismos partidários situacionistas, especialmente em períodos eleitorais e de crises políticas. A autora ressalta que:

Si bien el estado puede promover la participación, debetener cuidado de no cooptar a las organizaciones sea a través del control de su registroo del posible financiamiento; una organización sin autonomía, difícilmente puede serdemocrática ya que responderá en primer lugar a los intereses del gobierno o del partidogobernante y no a los intereses de la comunidad o a la identidad de la organización. Ademásde fortalecer los CC estimulando su autonomía, se deben atender las causas que dificultanla realización de un Plan Comunitario incluyente dentro de un contexto de polarizaciónpolítica y refinar las metodologías participativas para superar tales limitaciones y lograrlos objetivos propuestos (GARCIA-GUADILLA, 2018, p. 100).

Nesse cenário, ela entende que, ao se manter os entraves e as limitações no processo venezuelano, corre-se o risco de normalizar a exclusão e de tornar o Estado antidemocrático. Para GarciaGuadilla (2018), portanto, os problemas comunitários não se solucionam apenas com poder constitucional e recursos financeiros para as organizações sociais. Essa estratégia pode descambar para um resultado voluntário ou involuntário de perda de autonomia e potencialização das práticas de exclusão.

\section{Considerações finais}

A democracia chega ao século XXI teorizada das mais diversas formas. Mesmo que sua gênese direta e participativa tenha passado a ser entendida por denominações como representativa, participativa, parlamentar ou partidária, nenhuma delas foi capaz ainda de atender às urgências esperadas. Essa percepção demonstra a iminência, mesmo que tardia, para que se dissequem os seus paradoxos e as suas contradições, chegando-se, assim, ao estágio de um governo (democrático) que atenda às necessidades políticas, ideológicas e racionais da condição humana e que permita 
o seu vislumbre no horizonte da ação cotidiana, ou seja, a plena cidadania.

Nessa altura do século XXI, "democracia" é um termo verbalizado pelas mais diversas colorações políticas, muitas delas sem acreditar no seu potencial, assim o fazendo apenas pelo formalismo da retórica. Mais do que nunca, é importante que, em qualquer lugar que se tenha notícias de introdução de mecanismos de democracia participativa, estes sejam avaliados atentamente, por meio das metodologias inerentes às ciências humanas, suas virtudes e limitações.

O modelo participativo pode fortalecer a democracia e possivelmente substituir o modelo representativo, em que a participação se resume no procedimentalismo do voto. Essa transição, contudo, não ocorre de uma hora para outra, como em um passe de mágica. Em um primeiro momento, é possível contribuir para o fortalecimento da democracia representativa, para que, posteriormente, seja assumida a hegemonia do processo político pela participação, como resultado da tomada de consciência cidadã e dos benefícios coletivos oriundos da práxis participativa. Sendo assim, a efetivação de um modelo de participação que alce o cidadão à condição de sujeito dos processos políticos se apresenta como alternativa para uma sociedade em que esses sujeitos possam compreender o seu papel histórico, no momento em que tomem consciência de que as transformações na sociedade são perpassadas pela ação política coletiva.

Certamente, democratizar a democracia, conforme proposto por Santos e Avritzer (2002), é o horizonte a ser buscado, o desafio que se impõe, assim como identificar e executar as estratégias viáveis para o alcance de tal perspectiva. A ausência de ousadia para romper com os discursos e as práticas simplistas de não alteração de um modelo que não atende as necessidades mínimas de uma cidadania efetiva pode ser comparável ao ato de correr sem sair do lugar.

Mesmo que haja avaliações de que a participação popular remete a práticas populistas, não é prudente, de antemão, negar o estudo de fenômenos participativos. Seguramente, os experimentos do ser humano não estão imunes aos erros, às contradições e a 
certos equívocos, ainda mais quando se inicia uma nova tentativa, em um cenário adverso, sedimentado pelos tentáculos do sistema capitalista e neoliberal.

As novidades que a Revolução Bolivariana trouxe, por meio da Constituição de 1999 e pelas leis específicas das Misiones e dos Consejos Comunales, encontram tanto sinais de efetividade, quanto de contradições, em função de ser um processo revolucionário pacífico, distinguindo-se das várias revoluções ocorridas no país, ao longo dos séculos. A experiência participativa na Venezuela, proclamada inovadora em um cenário de descrédito da representação, deve ser refletida criticamente, visto que ainda carrega elementos patológicos da política tradicional, arraigada na sociedade por longos anos. Todo processo de mudança requer diagnósticos e avaliações de percurso para possíveis mudanças de rumo, especialmente para outorgar promessas contidas nos instrumentos legais e discursivos, com pretensões de construir uma democracia participativa e protagônica.

O socialismo do século XXI e a democracia participativa estão interligados no propósito de mudança e na emergência de um novo trilho para as relações humanas, políticas e sociais, na possibilidade, talvez utópica, de um movimento processual até um Estado Comunal, como expressão máxima do poder popular. Em grande medida, o que obstaculiza o alcance de um mundo melhor se expressa nos procedimentos levados a cabo pelo neoliberalismo, pelo capitalismo globalizado e pela forma exclusiva de representação, que bloqueiam os avanços na direção de uma sociedade humana, cooperativa, solidária e justa. É possível aventar que o modelo participativo de democracia aparece como articulador de uma cidadania plena, com possibilidade concreta de se evoluir para além de um conceito puramente teórico, para uma prática do que seja uma pujante democracia.

A Revolução Bolivariana, então, apresenta os desenhos de uma novidade, com vistas a um socialismo de novo tipo e alternativo ao capitalismo, sistema que em nenhum momento deu nem dará resposta às inúmeras demandas das sociedades por ele regidas. Essa ideia de um novo socialismo tem que sair do campo teórico e discursivo, para a crueza da prática e a convivência com o já 
moribundo sistema capitalista, que, mesmo cambaleante, ainda se apresenta forte o suficiente para dificultar a imposição em definitivo de novidades políticas e sociais necessárias.

\section{REFERÊNCIAS}

ADDOR, F. A participação popular, o nacional-estatismo e os governos progressistas no Equador e na Venezuela. In: FERRERAS, N. O. (org.). A questão nacional e as tradições nacional-estatistas no Brasil, América Latina e África. Rio de Janeiro: FGV, 2015. p. 139 - 164.

Teoria democrática e poder popular na América Latina. Florianópolis/SC: Insular, 2016.

BRUCE, M. A "democracia participativa e protagónica", o povo e o líder: a experiência dos consejos comunales na Parroquia 23 de Enero (Caracas/Venezuela). 2011. 253f. Dissertação (Mestrado em História Social) - Programa de Pós-Graduação em História Social, Universidade Federal Fluminense, Rio de Janeiro, 2011.

A "democratização da democracia" na Venezuela bolivariana: a experiência dos consejos comunales. In: FERRERAS, N. O. (org.). A questão nacional $e$ as tradições nacional-estatistas no Brasil, América Latina e África. Rio de Janeiro: FGV, 2015. p. 165 - 184.

CRBV - Constitución de la Repúplica Bolivariana de Venezuela. Gaceta Oficial Extraordinaria, n. 36.860, Caracas, 30 dic. 1999.

DAGNINO, E.; OLIVEIRA, A. J.; PANFICHI, A. (orgs.). A disputa pela construção democrática na América Latina. São Paulo: Paz e Terra, 2006.

DIETERICH, H. Hugo Chávez y el Socialismo del Siglo XXI. Caracas: Alcadía de Caracas, 2005.

EL TROUDI, H.; HARNECKER, M.; BONILLA, L. (orgs.). Ferramentas para participação: construindo o socialismo do século XXI. Fortaleza: UFC, 2010.

GARCÍA-GUADILLA, M. P. La experiencia de la democracia participativa: poder popular y planes de desarrollo comunitario en Venezuela. Espacio Abierto: Cuaderno Venezolano de Sociología, Caracas, v. 27, n. 1, p. 81 103, 2018.

GARCIA LINERA, A. América Latina y Europa, en espejo. In: FORO EMANCIPAÇÃO E IGAULDADE, DEBATE ALTERNATIVAS AO NEOLIBERALISMO, Buenos Aires, 12 - 15 mar. 2015. Disponível em: 
$<$ https://www.youtube.com/watch?v=vHPUX0cmEmI >. Acesso em: 30 out. 2018.

LANDER, E. Venezuela: a busca de um projeto contra-hegemônico. In: CECEÑA, A. E. (org.). Hegemonias e emancipações no século XXI. Buenos Aires: CLACSO, 2005. p. 193 - 218.

MASSAL, J. Democracia participativa: desafios y desencantos em el siglo XXI. Análisis Político, Bogotá, v. 23, n. 69, p. 79 - 91, 2010.

MIGUEL, L. F. Resgatar a participação: democracia participativa e a representação política no debate contemporâneo. Lua Nova: Revista de Cultura e Política, São Paulo, v. 100, n. 01, p. 83 - 118, 2017.

MPPCI-Ministerio del Poder Popular para la Comunicación y la Información. Misiones Bolivarianas. Caracas: [s.n.], maio 2007.

MPPC - Ministerio del Poder Popular para las Comunas. Sitio Oficial del Gobierno Bolivariano de Venezuela. Caracas, abr. 2016. Disponível em: <https://www.mpcomunas.gob.ve/>. Acesso em: 31 jul. 2019.

OM - Observatório Misiones. Venezuela Transparencia. Caracas, 21 mai. 2018. Disponível em: <https://transparencia.org.ve/>. Acesso em: 31 jul. 2019.

PEDRAZA MORA, A. ¿La democracia participativa: utopía o realidad? CRITERIOS: Cuadernos de Ciencias Jurídicas y Política Internacional, Bogotá, v. 8, n. 1, p. 71 - 101, 2014.

PETRAS, J. Referendo venezuelano: um post-morten e suas consequências. Tensões Mundiais, Fortaleza, v. 3, n. 5, p. 75 - 93, 2007.

POZNANSKI, F. Venezuela, essa terrível ditadura: uma viagem no país do autogoverno popular. Opera Mundi, São Paulo, 16 ago. 2019. Disponível em:<https://operamundi.uol.com.br/politica-e-economia/60006/ venezuela-essa-terrivel-ditadura-uma-viagem-no-pais-do-autogovernopopular>. Acesso em: 16 ago. 2019.

REVELES VÁZQUEZ, F. Democracia participativa para el fortalecimiento de la representación política: la experiencia latinoamericana. Andamios, Cidade do México, v. 14, n. 35, p. 01 - 28, 2017.

SANTOS, B. de S. Democratizar a democracia: os caminhos da democracia participativa. Rio de Janeiro: Civilização Brasileira, 2002.

Renovar a teoria crítica e reinventar a emancipação social. São Paulo: Boitempo, 2007.

A difícil democracia: reinventar as esquerdas. São Paulo: Boitempo, 2016. 
; AVRITZER, L. Introdução: para ampliar o cânone democrático. In: SANTOS, B. de S. Democratizar a democracia: os caminhos da democracia participativa. Rio de Janeiro: Civilização Brasileira, 2002. p. 39 -82 .

SANTOS, F. L. B. dos. Uma história da onda progressista sulamericana (1998 - 2016). São Paulo: Elefante, 2018.

TEIXEIRA, R. J. D. Transição democrática e modelos de democracia. Tensões Mundiais, Fortaleza, v. 11, n. 20, p. 199 - 223, 2015.

TERUGGI, Marco. La razón comunera. Blog Hastaelnocau, Buenos Aires, 29 jul. 2014. Disponível em: <https://hastaelnocau.wordpress. com/2014/07/29/77/>. Acesso em: 29 abr. 2019. 